\title{
Association of Subclinical Hypothyroidism with Dyslipidemia and Increased Carotid Intima-Media Thickness in Children
}

\author{
Edip Unal ${ }^{1}$, Alper Akın², Ruken Yıldırım ${ }^{1}$, Vasfiye Demir ${ }^{3}$, Ismail Yildiz ${ }^{4}$, Yusuf Kenan Haspolat ${ }^{1}$ \\ ${ }^{1}$ Dicle University Faculty of Medicine, Department of Pediatric Endocrinology, Diyarbakır, Turkey \\ ${ }^{2}$ Dicle University Faculty of Medicine, Department of Pediatric Cardiology, Diyarbakır, Turkey \\ ${ }^{3}$ Dicle University Faculty of Medicine, Department of Family Medicine, Diyarbakır, Turkey \\ ${ }^{4}$ Dicle University Faculty of Medicine, Department of Biostatistics, Diyarbakır, Turkey
}

\begin{abstract}
What is already known on this topic?
Subclinical hypothyroidism (SH) increases the intima-media thickness (CIMT) of the carotid artery. SH in children is also associated with increased total cholesterol (TC) and low-density lipoprotein cholesterol (LDL-C) levels as well as increased TC/high-density lipoprotein (HDL) and LDL/HDL ratios.
\end{abstract}

\section{What this study adds?}

Our study is of prime value since there are very few studies reporting on lipid profile abnormalities and increased CIMT in children with $\mathrm{SH}$, as opposed to a large number of studies in adults. The present study is the first study in the literature to show increased TC and LDL-C as well as increased TC/HDL and LDL/HDL ratios in non-obese children with SH.

\section{Abstract}

Objective: Subclinical hypothyroidism (SH) is defined as an elevated serum thyroid-stimulating hormone (TSH) level with free thyroxine $\left(\mathrm{fT}_{4}\right)$ level in the normal range. There are very few studies in the literature reporting on the effect of SH on lipid metabolism and carotid intima-media thickness (CIMT) in children.

Methods: The study included 38 children diagnosed with SH and a control group comprising 38 healthy, euthyroid children. SH was diagnosed based on an elevated TSH level (4.2-20 mIU/L) and normal fT 4 level measured in two morning fasting blood samples obtained at an interval of 2 to 6 weeks. Blood samples were collected by venipuncture in the morning after an overnight fast.

Results: The patient group included 38 children (16 male, 22 female) with SH and the control group -38 healthy, euthyroid children (20 male, 18 female). Mean age was $8.1 \pm 3.6$ (range, 3.5-15) years in the patient group and $8.9 \pm 2.4$ (range, 4.5-15) years in the control group. In the patient group, total cholesterol (TC), low-density lipoprotein cholesterol (LDL-C), TC/high-density lipoprotein cholesterol (HDL-C), and LDL-C/HDL-C were higher compared to the control group ( $p=0.049, p=0.014, p=0.002$, and 0.003 , respectively). In the patient group, CIMT was also significantly higher compared to the control group $(p=0.001)$. The patient group was further divided into two subgroups based on their serum TSH level: (I) patients with mildly elevated TSH (TSH $=4.2 \pm 10$ mIU/L) (n=33) and (II) patients with high TSH (TSH $\geq 10 \mathrm{mIU} / \mathrm{L})(\mathrm{n}=5)$. However, no significant difference was found between the patients with mild and severe SH with regard to TC, LDL-C, HDL-C, triglyceride level and CIMT levels $(p=0.635, p=0.424, p=0.310, p=0.342$, and 0.610, respectively).

Conclusion: Subclinical hypothyroidism leads to increased dyslipidemia (increased TC and LDL) and increased CIMT, which leads to increased risk of cardiovascular disease. Further studies are needed to substantiate these findings in children with SH.

Keywords: Subclinical hypothyroidism, carotid intima-media thickness, dyslipidemia, childhood

Address for Correspondence: Edip Unal MD,

Dicle University Faculty of Medicine, Department of Pediatric Endocrinology, Diyarbakır, Turkey

Phone: + 904122488001 E-mail: edip76@yahoo.com

${ }^{\circ}$ Copyright 2017 by Turkish Pediatric Endocrinology and Diabetes Society

The Journal of Clinical Research in Pediatric Endocrinology published by Galenos Publishing House.
Conflict of interest: None declared Received: 01.09 .2016 Accepted: 17.12 .2016 


\section{Introduction}

Subclinical hypothyroidism (SH) is defined as a state of elevated serum thyroid-stimulating hormone (TSH) level with a free thyroxine ( $\mathrm{fT}_{4}$ ) level in the normal range (1). Depending on the level of serum TSH, SH is divided into mild (TSH $=4.2-9.9 \mathrm{mIU} / \mathrm{L})$ and severe $(\mathrm{TSH} \geq 10 \mathrm{mIU} / \mathrm{L})$. Mild SH constitutes almost $75 \%$ of the patients with SH (2). SH affects $3-18 \%$ of the adult population and this prevalence increases with age (3). The prevalence of $\mathrm{SH}$ in children is reported to range between $1.7-9.5 \%(4,5)$. The most common cause of SH in children, as in adults, is Hashimoto's thyroiditis (4). There is no consensus on an ideal treatment for the management of SH. Moreover, whether dyslipidemia and increased carotid intima-media thickness (CIMT) in SH should be treated remains controversial.

Available data from adult studies and from few pediatric studies indicate that $\mathrm{SH}$ is associated with an alteration in lipid profile $(3,6,7)$. In addition, $\mathrm{SH}$ has also been shown to have impact on carbohydrate metabolism, the neuromuscular system, and on cognitive functions $(8,9)$. However, SH has its major effects on the cardiovascular system. Atherosclerosis is an important factor affecting the incidence of cardiovascular disease. Although there is no consensus on the association between $\mathrm{SH}$ and atherosclerosis, atherosclerosis is considered to be triggered by subintimal lipoprotein deposition and endothelial dysfunction. CIMT is used as a marker of atherosclerosis (2). Literature reviews show that the studies reporting on the effect of SH on lipid metabolism and CIMT have been mainly conducted in adults and that studies in children are sparse $(8,10)$. In this study, we evaluated lipid profile and CIMT in pediatric patients with SH.

\section{Methods}

The study included a patient group comprising 38 children diagnosed with $\mathrm{SH}$ and a control group comprising 38 healthy children with normal thyroid functions [serum TSF, free triiodothyronine $\left.\left(\mathrm{fT}_{3}\right), \mathrm{fT}_{4}\right]$ who presented to the Pediatric Endocrinology Department of Dicle University Faculty of Medicine, in Diyarbakır, Turkey, between AprilAugust 2016. Normal ranges of our laboratory were as follows: TSH $0.27-4.2 \mathrm{mIU} / \mathrm{L}, \mathrm{fT}_{3}$ 3.69-9.85 pmol/L, and $\mathrm{fT}_{4} 12-22.8 \mathrm{pmol} / \mathrm{L}$. The diagnosis of $\mathrm{SH}$ was based on an elevated TSH level (4.2-20 mIU/L) and normal $\mathrm{fT}_{4}$ level measured in two morning fasting blood samples obtained at an interval of 2 to 6 weeks.

No subject in the study or control group had any sign or symptom of hypertension, liver and kidney dysfunction, lung disease, systemic infection, or any chronic disease. Patients with diabetes mellitus, obesity, and a history of drug use were excluded from the study. In both groups, no participant was using any medication during the study. In all subjects, the electrocardiogram (ECG) showed normal sinus rhythm and conventional transthoracic echocardiography findings were normal. Prior to the study, a written consent was obtained from the parents of each subject and an ethical approval was received from the local ethics committee.

Serum TSH, $\mathrm{fT}_{3}$, and $\mathrm{fT}_{4}$ levels were determined by using a Cobos e601 analyzer (Roche HITACHI Germany) with electrochemiluminescence immunoassay (ECLIA) method. Blood samples were collected by venipuncture in the morning after an overnight fast. Serum levels of total cholesterol (TC), high-density lipoprotein cholesterol (HDL-C), and triglycerides (TG) were determined by using a photometric method (Abbott diagnostics $\mathrm{C} 16000$ chemistry analyzer, Illinois, USA). Calculation of the value of lowdensity lipoprotein cholesterol (LDL-C) was performed using the Friedewald formula (11)

\section{Carotid Intima-Media Thickness Measurements}

CIMT was determined by ultrasonographic images of the right carotid artery which were recorded with a $12 \mathrm{MHz}$ linear array transducer (Vivid S5 Pro, GE, Horten, Norway). The patient was placed in the supine position with the neck slightly extended and the head rotated $45^{\circ}$ to the opposite direction. The M-mode cursor was positioned $1.0 \mathrm{~cm}$ proximal to the right carotid artery bulb during end diastole. CIMT was accepted as the distance between the lumenintima and the media-adventitia interfaces. The CIMT on the frozen frame of a suitable longitudinal image was manually measured off-line. The value of CIMT was determined based on the mean value of a minimum of three measurements. All the CIMT evaluations were performed by an experienced pediatric cardiologist blinded to the clinical and biochemical characteristics of the patients.

\section{Statistical Analysis}

Data were analyzed using IBM SPSS 21.0 for Windows (SPSS Inc., Chicago, IL, USA). Quantitative variables were expressed as mean \pm standard deviation (SD) and categorical variables were presented as count and percentage (\%). Binary variables were compared by using independent samples t-test for normally distributed variables and by using Mann-Whitney U-test for non-normally distributed variables. Qualitative variables were compared by using chisquare test and the relationship among numerical variables was analyzed by using Pearson's correlation coefficient. The hypotheses were two-tailed and a $p$-value of $\leq 0.05$ was accepted statistically significant. 


\section{Results}

The patient group included 38 children (16 male, 22 female) with $\mathrm{SH}$ and the control group included 38 healthy, euthyroid children (20 male, 18 female). Mean age was $8.1 \pm 3.6$ (range, 3.5-15) years in the patient group and $8.9 \pm 2.4$ (range, 4.515) years in the control group. No significant difference was found between the groups with regard to age, gender, body weight, and SD score (SDS) values for body mass indices. Table 1 presents the demographic profiles of the subjects in the study and control groups.

In the patient group, TSH level was significantly higher $(\mathrm{p}<0.001)$ and the $\mathrm{fT}_{3}$ and $\mathrm{fT}_{4}$ levels were similar compared to the control group. Total TC, LDL, TC/HDL, and LDL/HDL were also higher in the patient group compared to the control group $(p=0.049, p=0.014, p=0.002$, and $p=0.003$, respectively). In the patient group, 9 children were detected as having high lipid levels. Of these, 3 children had high TC levels (max. 225 mg/dL), 5-high TG levels (max. $275 \mathrm{mg} / \mathrm{dL}$ ) and one patient had both high TG and TC levels. In the control group, 3 children had slightly high TG levels (max. $140 \mathrm{mg} / \mathrm{dL}$ ). CIMT was significantly higher in the patient group compared to the control group $(p=0.001)$. Table 2 presents the laboratory parameters and the CIMT values for both groups. There was no relationship between CIMT and lipid levels, and no correlations were detected between increasing lipid level and CIMT.

The patient group was further divided into two subgroups depending on serum TSH level: (I) patients with mildly elevated TSH $(\mathrm{TSH}=4.2 \pm 9.9 \mathrm{mIU} / \mathrm{L})(\mathrm{n}=33)$ and (II) patients with high TSH $(\mathrm{TSH} \geq 10 \mathrm{mIU} / \mathrm{L}) \quad(\mathrm{n}=5)$. No significant difference was found between the two subgroups with regard to TC, LDL-C, HDL-C, TG, and CIMT ( $p=0.635, p=0.424$, $p=0.310, p=0.342$, and $p=0.610$, respectively) (Table 3).

\section{Discussion}

The association between SH and lipid profile alteration has been reported in numerous studies $(6,7,12)$. Moreover, TSH

Table 1. Demographic characteristics of the study and control groups

\begin{tabular}{llll}
\hline & SH group $(\mathrm{n}=38)$ & Control group $(\mathrm{n}=38)$ & $\mathrm{p}$ \\
\hline Gender (Female/Male) & $22 / 16$ & $18 / 20$ & 0.818 \\
Age (years) & $8.1 \pm 3.6$ & $8.9 \pm 2.4$ & 0269 \\
& $6.3(3.5-15)$ & $8.2(4.5-15)$ & $28.2 \pm 8.3$ \\
Weight (kg) & $25.6 \pm 11.8$ & $26.6(16-57)$ & 0.277 \\
& $19.5(12.8-63)$ & $-0.39 \pm 0.90$ & 0.988 \\
SDS-BMI & $-0.43 \pm 0.94$ & $-0.10[-2.08-(1.18)]$ \\
\hline
\end{tabular}

Data are given as mean \pm standard deviation and median (range)

SH: subclinical hypothyroidism, SDS-BMI: standard deviation score of body mass index

Table 2. Biochemical characteristics and carotid intima-media thickness of the study groups

\begin{tabular}{|c|c|c|c|}
\hline & SH group $(n=38)$ & Control group $(n=38)$ & $\mathrm{p}$ \\
\hline \multirow[t]{2}{*}{$\mathrm{TSH}(\mathrm{mIU} / \mathrm{L}) *$} & $7.48 \pm 2.37$ & $2.35 \pm 0.82$ & $<0.001$ \\
\hline & $6.4(5-14.5)$ & $2.2(0.82-3.96)$ & \\
\hline $\mathrm{fT}_{4}(\mathrm{pmol} / \mathrm{L})$ & $16.40 \pm 1.80$ & $16.91 \pm 2.18$ & 0.269 \\
\hline $\mathrm{fT}_{3}(\mathrm{pmol} / \mathrm{L})$ & $6.71 \pm 0.68$ & $6.75 \pm 0.73$ & 0.811 \\
\hline TC $(\mathrm{mmol} / \mathrm{L})$ & $163.7 \pm 27.8$ & $153.6 \pm 20.6$ & 0.049 \\
\hline LDL-C (mmol/L) & $92.8 \pm 27.1$ & $79.7 \pm 17.0$ & 0.014 \\
\hline HDL-C (mmol/L) & $54.2 \pm 9.6$ & $57.8 \pm 9.3$ & 0.103 \\
\hline $\mathrm{TG}(\mathrm{mmol} / \mathrm{L})$ & $82.7 \pm 48.9$ & $74.9 \pm 28.6$ & 0.382 \\
\hline TC/HDL-C & $1.76 \pm 0.60$ & $1.40 \pm 0.36$ & 0.002 \\
\hline LDL/HDL-C & $10.83 \pm 3.60$ & $10.04 \pm 4.01$ & 0.003 \\
\hline CIMT & $0.05 \pm 0.019$ & $0.04 \pm 0.00$ & 0.001 \\
\hline
\end{tabular}

Data are given as mean \pm standard deviation

*Data are given as mean \pm standard deviation and median (range) *

CIMT: carotid intima-media thickness, $\mathrm{fT}_{3}$ : free triiodothyronine, $\mathrm{fT}_{4}$ : free thyroxine, HDL-C: high-density lipoprotein cholesterol,

LDL-C: low-density lipoprotein cholesterol, SH: subclinical hypothyroidism, TC: total cholesterol, TG: triglycerides, TSH: thyroid-stimulating hormone 
Table 3. Demographic characteristics, laboratory parameters, and carotid intima-media thickness values of the patients with thyroid-stimulating hormone $<10 \mathrm{mIU} / \mathrm{L}$ and thyroid-stimulating hormone $\geq 10 \mathrm{mIU} / \mathrm{L}$

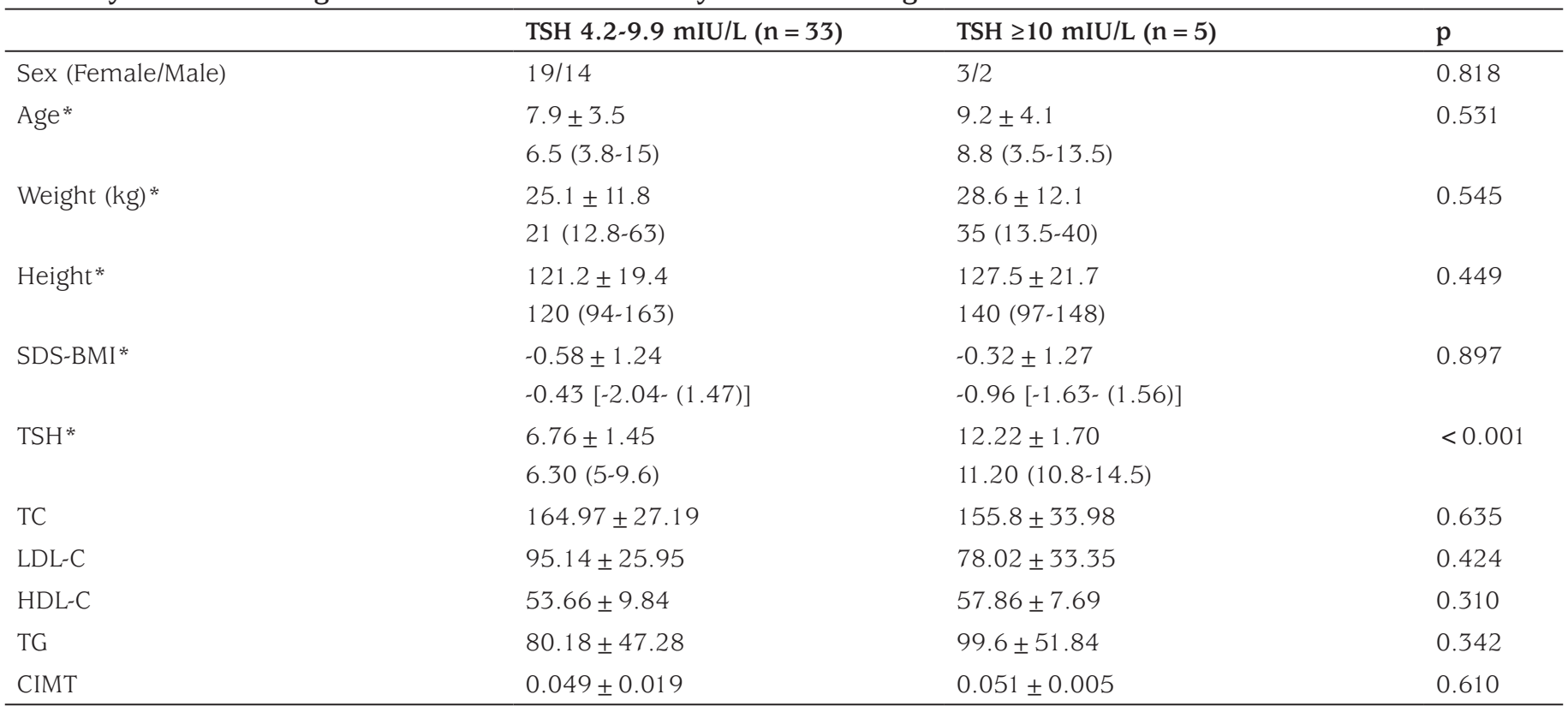

Data are given as mean \pm standard deviation

*Data are given as mean \pm standard deviation and median (range)*

HDL: high-density lipoprotein cholesterol, LDL-C: low-density lipoprotein cholesterol, SDS-BMI: standard deviation score of body mass index,

TC: total cholesterol, TG: triglycerides, CIMT: carotid intima-media thickness, TSH: thyroid-stimulating hormone

has been shown to induce the production of the hepatic 3-hydroxy-3-methyl-glutaryl coenzyme A (HMG CoA) reductase, which is a rate-limiting enzyme in cholesterol biosynthesis. Studies have also indicated that thyroid hormones may affect HDL metabolism by increasing the cholesteryl ester transfer protein activity and that they may also stimulate lipoprotein lipase (12).

The studies investigating the effect of $\mathrm{SH}$ on lipid profile alteration have reported contradictory findings. Although some studies found significant lipid profile changes in patients with SH $(6,7,12,13)$, some others did not (14). In most of the studies that found significant lipid profile changes, increased TC, TG, and LDL levels, and decreased HDL levels have been reported $(6,13,15,16,17,18)$.

Literature reviews indicate that studies investigating lipid profile changes in children with $\mathrm{SH}$ are few, as opposed to the large number of studies conducted in adults $(7,19,20,21)$. A previous study evaluated both children and adults with $\mathrm{SH}$ and found no lipid abnormality in children with TSH levels $<10 \mathrm{mIU} / \mathrm{L}$ and reported that the only abnormality was low HDL levels in children with TSH $>10 \mathrm{mIU} / \mathrm{L}$ compared to controls. The study also reported low HDL levels in adults with TSH > $10 \mathrm{mIU} / \mathrm{L}$ and, unlike in children, increased TC and LDL in adults (19). In our study on the other hand, no significant difference was found between the patients with
TSH $<10 \mathrm{mIU} / \mathrm{L}$ and those with TSH $\geq 10 \mathrm{mIU} / \mathrm{L}$ in terms of lipid profile. However, the small number of patients with TSH $\geq 10 \mathrm{mIU} / \mathrm{L}(\mathrm{n}=5)$ included in this comparison was a disadvantage. Çatlı et al (20) evaluated 27 children with SH and found no significant difference in TG, HDL, and LDL levels in these patients compared to controls and suggested that $\mathrm{SH}$ is not associated with dyslipidemia in children with SH. Paoli-Valeri et al (21) evaluated 17 children with SH aged between 2-9 years and found significantly low HDL-C levels in these patients. Sert et al (8) compared obese children with and without nonalcoholic fatty liver disease (NAFLD) and found increased TC and LDL and decreased HDL levels in patients with NAFLD compared to children without NAFLD. Contrariwise, in our study, we evaluated non-obese children with $\mathrm{SH}$ and, to our knowledge, there has been no study reporting on increased TC and LDL in non-obese children with $\mathrm{SH}$ in the literature. However, there are reports of several studies similar to our study suggesting that $\mathrm{SH}$ causes no significant difference in HDL-C level but may increase the TC/HDL-C or LDL-C/HDL-C ratios (6).

A correlation between CIMT and cardiovascular disease has been frequently reported in epidemiological studies, indicating that increased CIMT is a reliable marker for subclinical atherosclerosis (22). However, although the frequency of hypertension and dyslipidemia is remarkably high in patients with $\mathrm{SH}$, the association between $\mathrm{SH}$ 
and CIMT has been shown to be independent from these two conditions (8). In addition, another study showed that SH leads to increased risk of myocardial infarct and atherosclerosis, independent of serum cholesterol levels (23).

The correlation between $\mathrm{SH}$ and CIMT has mostly been reported in adult patients $(8,24,25,26)$. To our knowledge, there are only two publications in the literature reporting an increased CIMT in children with SH $(7,10)$. In one of these, Isik-Balci et al (11) evaluated 53 children with $\mathrm{SH}$ and reported that CIMT was significantly increased in children with $\mathrm{SH}$ compared to controls $(0.48 \pm 0.04 \mathrm{~mm}$ vs. $0.43 \pm 0.03$, respectively). The other study, which was conducted by Sert et al (8), found that CIMT was significantly increased in obese children with NAFLD compared to obese children without NAFLD and these authors have also reported that CIMT had a positive correlation with TSH. A meta-analysis investigating the correlation between $\mathrm{SH}$ and CIMT in adults concluded that CIMT was more prevalent in SH patients with TSH $>10 \mathrm{mIU} / \mathrm{L}$ and suggested that CIMT was increased in patients with TSH $<10 \mathrm{mIU} / \mathrm{L}$ as well, though slightly (8). Delitala et al (27) evaluated subclinical thyroid disorders (subclinical hypo- and hyperthyroidism) in 5,815 individuals aged between 14-102 years and reported that there was no association between these disorders and CIMT. However, the study had an important shortcoming since the TSH and $\mathrm{fT}_{4}$ measurements were performed only once; instead, these measurements should be repeated for a second time, since slightly increased TSH levels have been shown to return to normal in the subsequent measurement in almost $70 \%$ of the patients (28). To the best of our knowledge, the present study is the third study in the literature reporting a significantly increased CIMT in children with SH.

In conclusion, our study revealed increased TC, LDL-C, TC/HDL and LDL/HDL levels and a significant increase in CIMT in non-obese children with $\mathrm{SH}$, findings which have been scarcely reported in the literature. Since dyslipidemia and increased CIMT are accepted as risk factors for cardiovascular diseases, L-thyroxine could be considered for the treatment of SH. Future studies with larger sample sizes and longer periods of follow-up are needed to further substantiate the importance of L-thyroxine treatment in $\mathrm{SH}$ patients to decrease the risk of cardiovascular diseases.

\section{Ethics}

Ethics Committee Approval: Ethical approval was received from the local ethics committee.

Informed Consent: Prior to the study, a written consent was obtained from the parents of each subject.
Peer-review: Externally peer-reviewed.

\section{Authorship Contributions}

Concept: Edip Unal, Alper Akın, Design: Alper Akın, Edip Unal, Data Collection and Processing: Edip Unal, Alper Akın, Ruken Yıldırım, Vasfiye Demir, Yusuf Kenan Haspolat, İsmail Yıldız, Analysis and Interpretation: Alper Akın, Edip Unal, Ruken Yildırım, Yusuf Kenan Haspolat, İsmail Yıldız, Literature Research: Ruken Yıldırım, Alper Akın, Edip Unal, Vasfiye Demir, Writing: Alper Akın, Edip Unal, Vasfiye Demir.

Financial Disclosure: The authors declared that this study received no financial support.

\section{References}

1. Catlı G, Abaci A, Büyükgebiz A, Bober E. Subclinical hypothyroidism in childhood and adolescence. J Pediatr Endocrinol Metab 2014;27:10491057.

2. Lu M, Yang CB, Gao L, Zhao JJ. Mechanism of subclinical hypothyroidism accelerating endothelial dysfunction (Review). Exp Ther Med 2015;9:3 10. Epub 2014 Oct 27

3. Baumgartner C, Blum MR, Rodondi N. Subclinical hypothyroidism: summary of evidence in 2014. Swiss Med Wkly 2014;144:w14058.

4. Rizos CV, Elisaf MS, Liberopoulos EN. Effects of thyroid dysfunction on lipid profile. Open Cardiovasc Med J 2011;5:76-84. Epub 2011 Feb 24

5. Biondi B, Palmieri EA, Lombardi G, Fazio S. Subclinical hypothyroidism and cardiac function. Thyroid 2002;12:505-510.

6. Lee J, Chung WY. Subclinical Hypothyroidism; Natural History, LongTerm Clinical Effects and Treatment, Current Topics in Hypothyroidism with Focus on Development, Dr. Eliska Potlukova (Ed.), ISBN: 978-95351-0970-9, InTech, DOI: 10.5772/53688. 2013. Available from: http:// www.intechopen. com/books/current-topics-in-hypothyroidism-withfocus-ondevelopment/subclinical-hypothyroidism-natural-historylongterm-clinical-effects-and-treatment.

7. Efstathiadou Z, Bitsis S, Milionis HJ, Kukuvitis A, Bairaktari ET, Elisaf MS, Tsatsoulis A. Lipid profile in subclinical hypothyroidism: is L-thyroxine substitution beneficial? Eur J Endocrinol 2001;145:705-710.

8. Sert A, Pirgon O, Aypar E, Yilmaz H, Odabas D. Subclinical hypothyroidism as a risk factor for the development of cardiovascular disease in obese adolescents with nonalcoholic fatty liver disease. Pediatr Cardiol 2013;34:1166-1174. Epub 2013 Jan 24

9. Gao N, Zhang W, Zhang YZ, Yang Q, Chen SH. Carotid intima-media thickness in patients with subclinical hypothyroidism: a meta-analysis. Atherosclerosis 2013;227;18-25. Epub 2012 Nov 6

10. Ergür AT, Taner Y, Ata E, Melek E, Bakar EE, Sancak T. Neurocognitive functions in children and adolescents with subclinical hypothyroidism. J Clin Res Pediatr Endocrinol 2012;4:21-24

11. Isik-Balci Y, Agladioglu S, Agladioglu K, Kilic-Toprak E, Kilic-Erkek O, Ozhan B, Polat A, Bor-Kucukatay M. Impaired Hemorheological Parameters and Increased Carotid Intima-Media Thickness in Children with Subclinical Hypothyroidism. Horm Res Paediatr 2016;85:250256. Epub 2016 Mar 3

12. Rifai N, Warnick GR, McNamara JR, Belcher JD, Grinstead GF, Frantz ID Jr. Measurement of low-density-lipoprotein cholesterol in serum: a status report. Clin Chem 1992;38:150-160. 
13. Canaris GJ, Manowitz NR, Mayor G, Ridgway EC. The Colorado thyroid disease prevalence study. Arch Intern Med 2000;160:526-534.

14. Park YJ, Lee EJ, Lee YJ, Choi SH, Park JH, Lee SB, Lim S, Lee WW, Jang HC, Cho BY, Woo JI, Kim KW. Subclinical hypothyroidism $(\mathrm{SCH})$ is not associated with metabolic derangement, cognitive impairment, depression or poor quality of life (QoL) in elderly subjects. Arch Gerontol Geriatr 2010;50:68-73. Epub 2009 Jul 9

15. Iqbal A, Jorde R, Figenschau Y. Serum lipid levels in relation to serum thyroid-stimulating hormone and the effect of thyroxine treatment on serum lipid levels in subjects with subclinical hypothyroidism: the Tromso Study. J Intern Med 2006;260:53-61.

16. Jung $\mathrm{CH}$, Sung KC, Shin HS, Rhee EJ, Lee WY, Kim BS, Kang JH, Kim H, Kim SW, Lee MH, Park JR, Kim SW. Thyroid dysfunction and their relation to cardiovascular risk factors such as lipid profile, hsCRP, and waist hip ratio in Korea. Korean J Intern Med 2003;18:146-153.

17. Milionis HJ, Tambaki AP, Kanioglou CN, Elisaf MS, Tselepis AD, Tsatsoulis A. Thyroid substitution therapy induces high-density lipoprotein-associated platelet-activating factor-acetylhydrolase in patients with subclinical hypothyroidism: a potential antiatherogenic effect. Thyroid 2005;15:455-460.

18. Toruner F, Altınova AE, Karakoç A, Yetkin I, Ayvaz G, Cakir N, Arslan M. Risk factors for cardiovascular disease in patients with subclinical hypothyroidism. Adv Ther 2008;25:430-437.

19. Marwaha RK, Tandon N, Garg MK, Kanwar R, Sastry A, Narang A, Arora $\mathrm{S}$, Bhadra K. Dyslipidemia in subclinical hypothyroidism in an Indian population. Clin Biochem 2011;44:1214-1217. Epub 2011 Jul 19

20. Çatlı G, Anık A, Ünver Tuhan H, Böber E, Abacı A. The effect of L-thyroxine treatment on hypothyroid symptom scores and lipid profile in children with subclinical hypothyroidism. J Clin Res Pediatr Endocrinol 2014;6:238-244.
21. Paoli-Valeri M, Guzman M, Jimenez-Lopez V, Arias-Ferreira A, BricenoFernandez M, Arata-Bellabarba G. Atherogenic lipid profile in children with subclinical hypothyroidism. An Pediatr (Barc) 2005;62:128-134.

22. Simon A, Megnien JL, Chironi G. The value of carotid intima-media thickness for predicting cardiovascular risk. Arterioscler Thromb Vasc Biol 2010;30:182-185. Epub 2009 Nov 30

23. Wang CY, Chang TC, Chen MF. Associations between subclinical thyroid disease and metabolic syndrome. Endocr J 2012;59:911-917. Epub 2012 Jul 5

24. Valentina VN, Marijan B, Chedo D, Branka K. Subclinical hypothyroidism and risk to carotid atherosclerosi. Arq Bras Endocrinol Metabol 2011;55:475-480.

25. Kim SK, Kim SH, Park KS, Park SW, Cho YW. Regression of the increased common carotid artery-intima media thickness in subclinical hypothyroidism after thyroid hormone replacement. Endocr J 2009;56:753-758. Epub 2009 Jun 9

26. Monzani F, Caraccio N, Kozakowa M, Dardano A, Vittone F, Virdis A, Taddei S, Palombo C, Ferrannini E. Effect of levothyroxine replacement on lipid profile and intima-media thickness in subclinical hypothyroidism: a double-blind, placebo controlled study. J Clin Endocrinol Metab 2004;89:2099-2106.

27. Delitala AP, Filigheddu F, M. Orru M, AlGhatrif M, Steri M, Pilia MG, Scuteri A, Lobina M, Piras MG, Delitala G, Lakatta EG, Schlessinger D, Cucca F. No evidence of association between subclinical thyroid disorders and common carotid intima medial thickness or atherosclerotic plaque. Nutr Metab Cardiovasc Dis 2015;25:1104-1110. Epub 2015 Oct 21

28. Lazar L, Frumkin RB, Battat E, Lebenthal Y, Phillip M, Meyerovitch J. Natural history of thyroid function tests over 5 years in a large pediatric cohort. J Clin Endocrinol Metab 2009;94:1678-1682. Epub 2009 Feb 24 